University of the Pacific

Scholarly Commons

All Faculty Articles - School of Engineering and Computer Science

All Faculty Scholarship

$11-1-2016$

\title{
$25+$ years of the hubble space telescope and a simple error that cost millions
}

\section{Said Shakerin}

University of the Pacific, sshakerin@pacific.edu

Follow this and additional works at: https://scholarlycommons.pacific.edu/soecs-facarticles

Part of the Mechanical Engineering Commons

\section{Recommended Citation}

Shakerin, S. (2016). 25+ years of the hubble space telescope and a simple error that cost millions.

Physics Teacher, 54(8), 480-481. DOI: 10.1119/1.4965269

https://scholarlycommons.pacific.edu/soecs-facarticles/90

This Article is brought to you for free and open access by the All Faculty Scholarship at Scholarly Commons. It has been accepted for inclusion in All Faculty Articles - School of Engineering and Computer Science by an authorized administrator of Scholarly Commons. For more information, please contact mgibney@pacific.edu. 


\section{$\bigcap_{0}^{\frac{1}{0}}$ \\ 25+ Years of the Hubble Space Telescope and a Simple Error that Cost Millions}

Cite as: Phys. Teach. 54, 480 (2016); https://doi.org/10.1119/1.4965269

Published Online: 19 October 2016

\section{Said Shakerin}

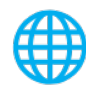

\section{ARTICLES YOU MAY BE INTERESTED IN}

Inexpensive Audio Activities: Earbud-based Sound Experiments

The Physics Teacher 54, 500 (2016); https://doi.org/10.1119/1.4965276

Pedagogical Techniques Employed by the Television Show "MythBusters"

The Physics Teacher 54, 476 (2016); https://doi.org/10.1119/1.4965268

Multiple-Choice Answers: To Change or Not to Change? Perhaps Not Such a Simple Question

The Physics Teacher 54, 469 (2016); https://doi.org/10.1119/1.4965266

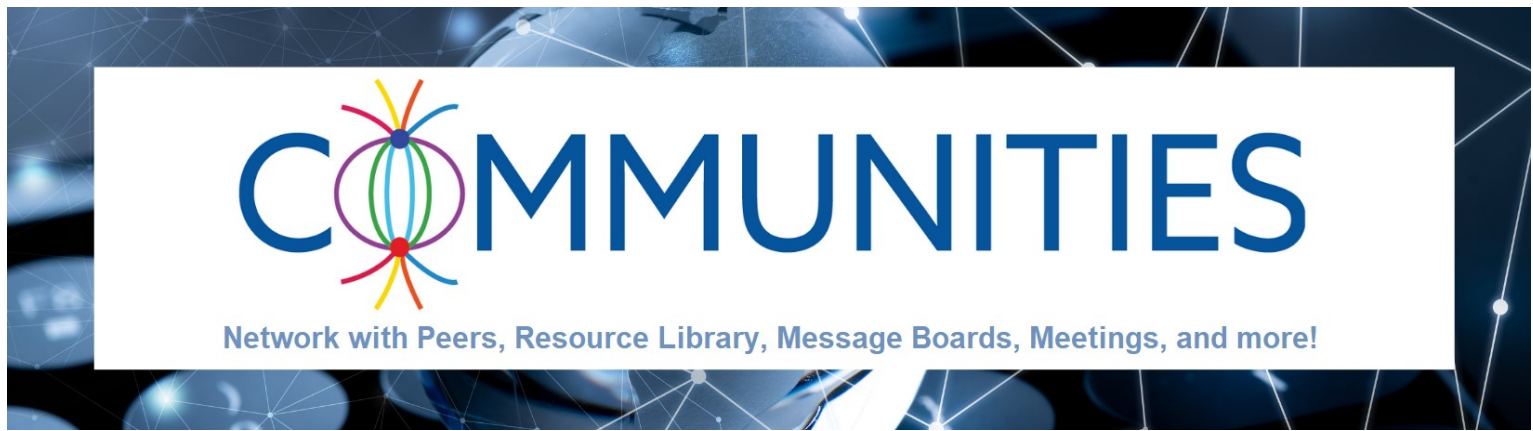




\section{$25+$ Years of the Hubble Space Telescope and a Simple Error that Cost Millions}

Said Shakerin, University of the Pacific, Stockton, CA

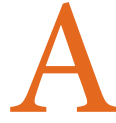
simple mistake in properly setting up a measuring device caused millions of dollars to be spent in correcting the initial optical failure of the Hubble Space Telescope (HST). ${ }^{1}$ This short article is intended as a lesson for a physics laboratory and discussion of errors in measurement.

The year 2015 marked the 25th anniversary of the HST, which has made extraordinary contributions to astrophysics. $^{2}$ The telescope is named in honor of Edwin P. Hubble (1889-1953), who proved there are other galaxies beyond the Milky Way. Space, as opposed to ground, telescopes offer unobstructed views beyond Earth's

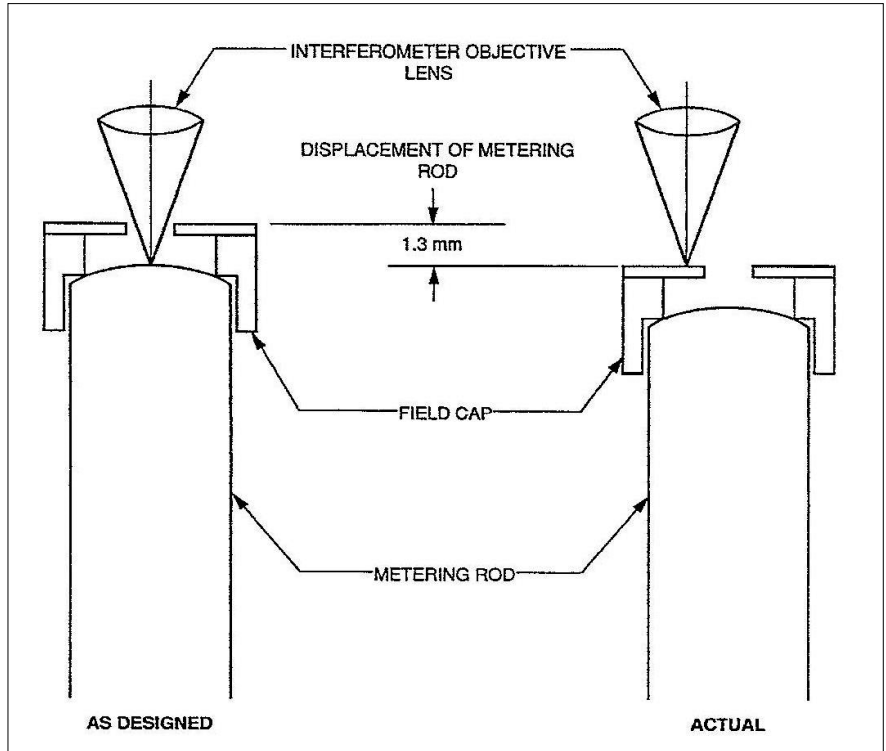

Fig. 1. Displacement due to the interferometer focusing on the field cap instead of the metering rod. The location where spacers were added is not included in this figure. Figure source: Ref. 3, p. 7-8. atmosphere and its associated

turbulence and absorption. NASA announced the HST program in cooperation with the European Space Agency, and the U.S. Congress approved funding in 1977.

After delays and budget overruns, the HST was launched aboard space shuttle Discovery in April 1990. Astrophysicists around the world thought their dreams had come true. They were waiting for the images, which were expected to be sharper than the best images that had been obtained from the ground. Unfortunately, the images came in blurred and the telescope could not be refocused to fix the problem. After two months of analysis, it was announced that the low image quality was due to spherical aberration because the primary mirror was not polished to the correct curvature. (Spherical aberration is an optical flaw in mirrors and lenses. For example, in a spherical mirror reflected light beams from areas near its edge do not go through the same point as reflected light beams from near its center, creating a blurred image.) An investigative board was charged to find out how this had happened, and why it had not been discovered prior to the launch. The board delivered its report in November $1990 .{ }^{3}$ It should be noted that due to lapses in documentation, it was difficult to reconstruct exactly what had happened but the report identified the most probable case.

The primary mirror of the HST is $2.4 \mathrm{~m}$ in diameter, which is very large and required special fabrication to meet strict performance requirements. NASA contracted Perkin-Elmer Corporation (P-E) to fabricate the optics. P-E ground and polished a glass disk and then coated it with a very thin aluminum film to make the primary mirror. The grinding/polishing was a laborious process and had to be done under controlled conditions. P-E designed and built a precision optical instrument, the reflective null corrector (RNC), to allow its operators to check the mirror's curvature during polishing until a specified shape was attained. The RNC had successfully been used earlier to fabricate a smaller mirror to prove the company's technical capability to NASA. For work on the larger mirror, the RNC needed to be set up accordingly.

The setup process included positioning a metering rod that separated optical elements within the RNC. The rod had a reflective end on which a laser beam would be shined, and from the beam's reflection and its interference with the incoming beam the proper positioning would proceed. The rod end was retained in a field cap with a central aperture (for the passage of the laser beam). The field cap had a nonreflecting coating. Unfortunately, a small area on the field cap adjacent
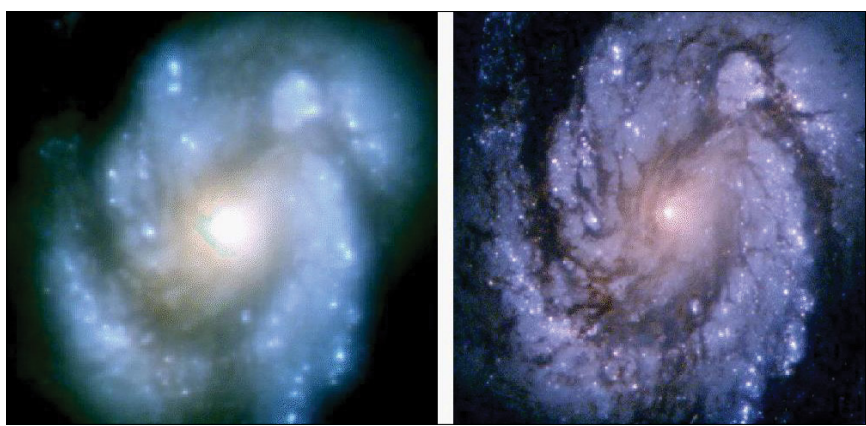

Fig. 2. Hubble's view of the M100 Galactic Nucleus before (left) and after (right) corrective optics were installed. (Image credit: NASA/STSCI/JPL) 
to the aperture was missing its non-reflective coating. When the operator looked at the reflected laser beam, it was from the area where the nonreflecting coating was missing, and not from the rod's end as it should have been for proper positioning. Figure 1 schematically shows the setup. Not noticing the mistake, spacers (not included in the design) were added to the RNC to finalize the positioning. The RNC design team was in a different division of the corporation and, apparently, was not made aware of the spacers. From then on, the RNC had a simple but gross error as it was improperly set. This was the technical root cause of the resulting spherical aberration problem with the mirror. Unfortunately, the RNC was not verified independently. Thus, the mirror was polished to a slightly wrong shape, which was too flat near its edge to produce sharp images.

This is a grand example of a mirror that was made precisely but not accurately. The mirror's curvature error at its edge was $2.2 \mu \mathrm{m}$ (less than 0.1 thousandths of an inch). ${ }^{4}$ This seemingly tiny error in such a large mirror was enough to cause the spherical aberration. Of course there were failures of quality assurance along the course of fabrication as engineers did notice issues that something was not right, but, under critical (budgetary and scheduling) pressure, the issues were not properly addressed. There were other complicating organizational factors that led to the optical failure. Interested readers can find short descriptions of those factors in a fourpage case study published by NASA ${ }^{5}$ or in details in the board report. $^{3}$

Remarkably and ingeniously, the HST team came up with corrective devices that were added to the optical path of the telescope during several spacewalks in December 1993. (Details can be found in the Wikipedia article on HST. ${ }^{2}$ ) Sharper, focused images have been transmitted since. For example, Fig. 2 shows a comparison between blurred and corrected images of M100 Galactic Nucleus. The HST has continued its remarkable mission far longer than the originally specified 15 years, and is considered one of the longest and most successful science missions ever.

For classroom activity, it would be instructive to encourage students to read the HST history in preparation for class discussion. A few example questions to start the discussion are listed below. The reference(s) cited in each question can be consulted to find out the answer to that question.

A. What are the advantages of space compared with ground telescopes? ${ }^{1,2}$

B. What are some of the discoveries of the HST? ${ }^{1,2}$

C. What were some of the factors that contributed to the HST initial optical failure? ${ }^{3,5}$

$D$. What was the impact of this failure on Perkin-Elmer Corporation and its reputation? ${ }^{5}$

$E$. What are the lessons learned from this failure? ? $^{3,6}$
Aside from the complexity that was briefly mentioned above, and in a summary, it is important to emphasize the following points in physics laboratory teaching.

1. Simple error at the component level can lead to costly system-level failure.

2. Improvisation during testing, not called for in the design, should be verified with the designer.

3. Double, independent checking is an effective way to detect errors.

\section{Acknowledgments}

The author would like to thank two anonymous reviewers for their helpful comments that improved the article. Dr. Ronald Allen, Space Telescope Science Institute, clarified the magnitude of the error and provided copies of relevant pages of the report cited in Ref. 4.

\section{References}

1. For a brief history of the Hubble Space Telescope, visit http://www.history.nasa.gov/hubble/index.html . For a detailed account of the Hubble Space Telescope, visit https://en.wikipedia.org/wiki/Hubble_Space_Telescope .

2. For extensive information, including a free e-book, about the 25th-year anniversary of the Hubble Space Telescope and more, visit http://hubble25th.org/.

3. "The Hubble Space Telescope Optical Systems Failure Report," NASA-TM-103443 (Nov. 1990), (available online, enter title in search engine.)

4. "Report of the HST Strategy Panel: A Strategy for Recovery," edited by R. A. Brown and H .C. Ford (Space Telescope Science Institute, Baltimore, MD, 1990), p. 74, and R. L. White and C. J. Burrows, "The HST Spherical Aberration and its Effects on Images," in The Restoration of HST Images and Spectra: Proceedings of a Workshop Held at the Space Telescope Science Institute, edited by R. L. White and R. J. Allen (Baltimore, MD, 1990), pp. 2-6.

5. “Communication Aberration," NASA, System Failure Case Studies (July 2011), https://nsc.nasa.gov/SFCS/

SystemFailureCaseStudy/Details/70.

6. C. Pellerin, How NASA Builds Teams: Mission Critical Soft Skills for Scientists, Engineers, and Project Teams (Wiley, Hoboken, NJ, 2009).

Said Shakerin is a professor at the University of the Pacific. He received his mechanical engineering education from universities in Iran and the U.S., with a PhD from Colorado State University in 1986. He enjoys developing fluids-based demonstration devices for use in classroom or outreach.

Department of Mechanical Engineering, University of the Pacific, Stockton, CA 95211; sshakerin@pacific.edu 